\title{
CRESCIMENTO E ACÚMULO DE NUTRIENTES POR PLANTAS ESPONTÂNEAS E POR LEGUMINOSAS UTILIZADAS PARA ADUBAÇÃO VERDE ${ }^{(1)}$
}

\author{
C. FAVERO(2), I. J UCKSCH(3), L.M. $\operatorname{COSTA}^{(3)}$, \\ R. C. ALVARE NGA ${ }^{(4)} \&$ J . C. L. NEVES $S^{(3)}$
}

\begin{abstract}
RESUMO
As espécies vegetais espontâneas, nas áreas de cultivo agrícola, têm sido tratadas como "plantas daninhas", "ervas invasoras", "inços" e outras denominações, do ponto de vista dos prejuízos que podem acarretar às espécies cultivadas. No entanto, as espontâneas podem promover os mesmos efeitos de proteção do solo e ciclagem de nutrientes que espécies culti vadas ou introduzi das para adu bação verde. 0 cresci mento e o acúmulo de nutrientes pela parte aérea de espontâneas e de legumi nosas utilizadas como adubos verdes foram medidos em um experimento de campo em Sete Lagoas (MG), na E mbrapa Milho e Sorgo. O experimento consistiu de cinco espécies de leguminosas (feijão-de-porco, feijãobravo do Ceará, mucuna-preta, lab-lab e guandu), submeti das a duas condições de manejo (com e sem capina), e uma testemunha (somente espontâneas). No florescimento das leguminosas, foram obtidos a massa da matéria seca e o teor de nutrientes da parte aérea de cada espécie de leguminosa e das espontâneas presentes nas parcelas. $\mathbf{O}$ sistema com apenas as espontâneas produziu menos bi omassa e acumulou menos nutrientes que os sistemas com leguminosas. Foram poucas as espontâneas que apresentaram teor es de carbono, cálcio e nitrogênio próxi mos ou superiores aos das leguminosas. No entanto, para potássio, magnésio e fósforo, ocorreu o inverso. A maioria das espontâneas apresentou teores de potássio, magnésio e de fósforo superiores aos das leguminosas, destacando-se: Portulaca oleracea, Euphorbia heterophylla, Bidens pilosa, Commelina benghalensis e Melanpodium perfoliatum.
\end{abstract}

Termos de indexação: produtividade de biomassa, ciclagem de nutrientes, invasoras.

(1) Parte da Tese de Mestrado do primeiro autor. Recebido para publicação em maio de 1999 e aprovado em fevereiro de 2000.

(2) Doutorando em Solos e Nutrição de Plantas na Universidade Federal de Viçosa - UFV. e-mail: clf@solos.ufv.br CEP $36571-000$ Viçosa (MG).

(3) Professor do Departamento de Solos da UFV. CEP 36571-000 Viçosa (MG).

(4) Pesquisador da E mbrapa Milho e Sorgo. Cx. Postal 151, CEP 35701-970 Sete Lagoas (MG). 


\title{
SUMMARY: BIOMASS PRODUCTIVITY AND NUTRIENT ACCUMULATION BY SPONTANEOUS AND LEGUMINOUS SPECIES USED FOR GREEN MANURE
}

\begin{abstract}
Spontaneous plant species in agricultural areas havebeen regarded as weds, invasi ve or unwanted plants, when consi dering thedamages that they can bring to cultivated species. However, spontaneous species can bring about thesameeffects of soil protection and nutrient cycling that cul tivated or introduced species used for green manuredo. Biomass productivity and nutrient accumulation for theaerial part of spontaneous and leguminous plants used as green fertilizers weremeasured at theexperimental stati on E mbrapa Corn and Sorghum, in Sete Lagoas, Minas Gerais (Brazil). The experiment comprised five leguminous species (Canavalia ensiformes, Canavalia brasiliensis, Mucuna aterrima, dolichos lablab and Cajanus cajan) tested in two growing conditions (with and without weeding), and a control (only spontaneous species). At flowering of theleguminous species, dry matter and nutrient level of theaerial part, for each leguminous and spontaneous species present in the parcels, were obtained. Thesystem which had only spontaneous species produced less biomass and accumulated less nutrient than thesystems with legumi nous species. Few spontaneous species presented carbon, calcium and nitrogen levels which were close to or larger than the leguminous one. However, theinverseoccurred for potassium, magnesium and phosphorus. M ost spontaneous species presented potassi um and magnesi um levels, and several of them, phosphorus levels, larger than the leguminous ones. With regard to levels of phosphorus, potassium and magnesium, thefol lowing spontaneous species stood out: Portulaca oleracea, Euphorbia heterophylla, Bidens pilosa, Commelina benghalensis and Melanpodium perfoliatum.
\end{abstract}

Index terms: biomass productivity, nutrient cycling, invasive.

\section{INTRODUÇÃO}

As leguminosas têm sido as espécies preferidas para adubação verde. A principal razão é a fixação do nitrogênio atmosférico por bactérias, principalmente do gênero R hizobium, que vivem em simbiose com suas raízes. Além disso, produzem grande quantidade de massa e apresentam sistema radicular pivotante, capaz de extrair nutrientes que se encontram em camadas mais profundas do solo, os quais serão disponibilizados após sua decomposição e incorporação ao sol o (Kiehl, 1960; Schaaffhausen, 1968).

Existe grande variação na produtividade de biomassa das leguminosas, conforme as condições nas quais elas crescem. U ma das espécies que se destaca é o feijão-guandu, com produtividade de 17,9 t ha-1 de massa de matéria seca (Alvarenga et al., 1995). Para o feijão-de-porco e para a mucunapreta, os mesmos autores obtiveram 5,3 e 7,1 t ha-1 de massa de matéria seca, enquanto De-polli \& Chada (1989) obtiveram 6,0 e 4,4 t ha-1, respectivamente. Bowen (1987), citado por Lathwell (1990), conseguiu produtividade de $8,5 \mathrm{t} \mathrm{ha}^{-1}$ de massa de matéria seca de mucuna-preta.

A quantidade de nutrientes acumulada é proporcional à quantidade de biomassa produzida, variando, entreas espécies, a eficiência deabsorção.
Trabalhando com diferentes espécies de leguminosas, Alvarenga et al. (1995) destacaram o feijão-guandu como a espécie que imobilizou as maiores quantidades de N, P e K $(336,2,20,9$ e $180,7 \mathrm{~kg} \mathrm{ha}-1$, respectivamente), sendo estas diretamente relacionadas com a mai or produtividade de massa de matéria seca (17,9 t ha-1). Manhães \& Cruz Filho (1983), estudando diversas leguminosas, verificaram que os maiores teores de nutrientes foram observados na mucuna-preta, no guandu eno feijão-de-porco.

As espécies vegetais espontâneas, nas áreas de cultivo agrícola, têm sido tratadas como "plantas daninhas", "ervas invasoras", "inços" e outras denominações, do ponto de vista dos prejuízos que podem acarretar às espécies cultivadas, por competir com estas em nutrientes, água eluz. No entanto, as espécies espontâneas podem promover os mesmos efeitos de cobertura do sol o, produção de bi omassa e ciclagem de nutrientes que as espécies introduzidas ou cultivadas para adubação verde.

Qasem (1992) estudou o acúmulo de nutrientes por espontâneas, comparando-o com feijoeiro e tomateiro. Excetuando uma das espécies de espontâneas estudadas, as demais apresentaram, na parte aérea das plantas, maiores teores de N, P e K que ofeijoei ro e otomateiro; apresentaram, também, maiores teores de $\mathrm{Mg}$ que o feijoeiro. Em estudo 
realizado por Parylak (1994), o teor de nutrientes em espontâneas foi maior que em triticale, duas vezes para $\mathrm{N}$ e $\mathrm{P}$, três vezes para $\mathrm{Ca}$ e cinco vezes para K.

O presente trabal ho teve o objetivo de avaliar o desempenho de espécies espontâneas e de cinco leguminosas utilizadas para adubação verde, quanto à produtividade de biomassa e acúmulo de nutrientes pela parte aérea das plantas.

\section{MATE RIAL E MÉTODOS}

Foi instalado um experimento no campo, em Sete Lagoas (MG), na E mbrapa Milho eSorgo, localizada a $19^{\circ} 28^{\prime}$ LatitudeSul, Longitude $44^{\circ} 15^{\prime} 08^{\prime \prime}$ W GrW e Altitude de $732 \mathrm{~m}$. O experimento compreendeu uma área total de $1.460 \mathrm{~m}^{2}$, local izada numa encosta, em um Latossolo Vermel ho-Escuro A moderado textura argila fase cerrado subcaducifólio relevo suave ondulado. Dados de análises químicas efísicas de uma amostra composta de solo, col etada na área do experimento antes de sua instalação, estão apresentados no quadro 1 . As características climáticas do local, durante o experimento, segundo os dados obtidos na estação meteorológica da Embrapa Milho e Sorgo, encontram-se na figura 1.

O experimento foi constituído de cinco espécies de leguminosas: feijão-de-porco - FdP (Canavalia ensi formes), feijão-bravo do Ceará - FbC (Canavalia brasiliensis), mucuna-preta - Muc (Mucuna aterrima), lab-lab - Lab (Dol ichos lablab) e guandu Gua (Cajanus cajan), submetidas a duas condições de manejo (com e sem capina). Os manejos foram arranjados em faixas dentro de cada leguminosa.
I ncluiu-se também um tratamento sem leguminosa, em que a faixa sem capina serviu como testemunha - Tes (somente espontâneas). Os tratamentos foram distribuídos em blocos casualizados, com quatro repetições.

Quadro 1. Resultados das análises químicas efísicas de amostra do solo da área do experimento

\begin{tabular}{|c|c|c|}
\hline \multirow{2}{*}{ Característica } & \multicolumn{2}{|c|}{ Profundidade $(\mathrm{cm})$} \\
\hline & $0-20$ & $20-40$ \\
\hline pH (água) & 5,7 & 5,5 \\
\hline $\mathrm{pH}(\mathrm{KCl})$ & 5,28 & 4,85 \\
\hline$P\left(\mathrm{mg} \mathrm{dm}^{-3}\right)$ & 12,0 & 7,0 \\
\hline M.O. $\left(\mathrm{g} \mathrm{kg}^{-1}\right)$ & 33,0 & 26,6 \\
\hline $\mathrm{Al}^{3+}\left(\mathrm{cmol}_{\mathrm{c}} \mathrm{dm}^{-3}\right)$ & 0,0 & 0,0 \\
\hline $\mathrm{H}+\mathrm{Al}\left(\mathrm{cmol}_{\mathrm{c}} \mathrm{dm}^{-3}\right)$ & 3,42 & 3,78 \\
\hline $\mathrm{Ca}^{2+}\left(\mathrm{cmol}_{\mathrm{c}} \mathrm{dm}^{-3}\right)$ & 5,01 & 3,01 \\
\hline $\mathrm{Mg}^{2+}\left(\mathrm{cmol}_{\mathrm{c}} \mathrm{dm}^{-3}\right)$ & 0,70 & 0,43 \\
\hline $\mathrm{K}^{+}\left(\mathrm{cmol}_{\mathrm{c}} \mathrm{dm}^{-3}\right)$ & 0,19 & 0,08 \\
\hline $\mathrm{S}\left(\mathrm{cmol}_{\mathrm{c}} \mathrm{dm}^{-3}\right)$ & 5,90 & 3,52 \\
\hline$V(\%)$ & 63,30 & 48,25 \\
\hline Equivalente de umidade (\%) & 30,09 & 30,20 \\
\hline Argila dispersa em água (\%) & 26 & 28 \\
\hline Areia (\%) & 18 & 15 \\
\hline Silte (\%) & 32 & 25 \\
\hline Argila (\%) & 50 & 60 \\
\hline Classe textural & Argila & Muito argiloso \\
\hline
\end{tabular}

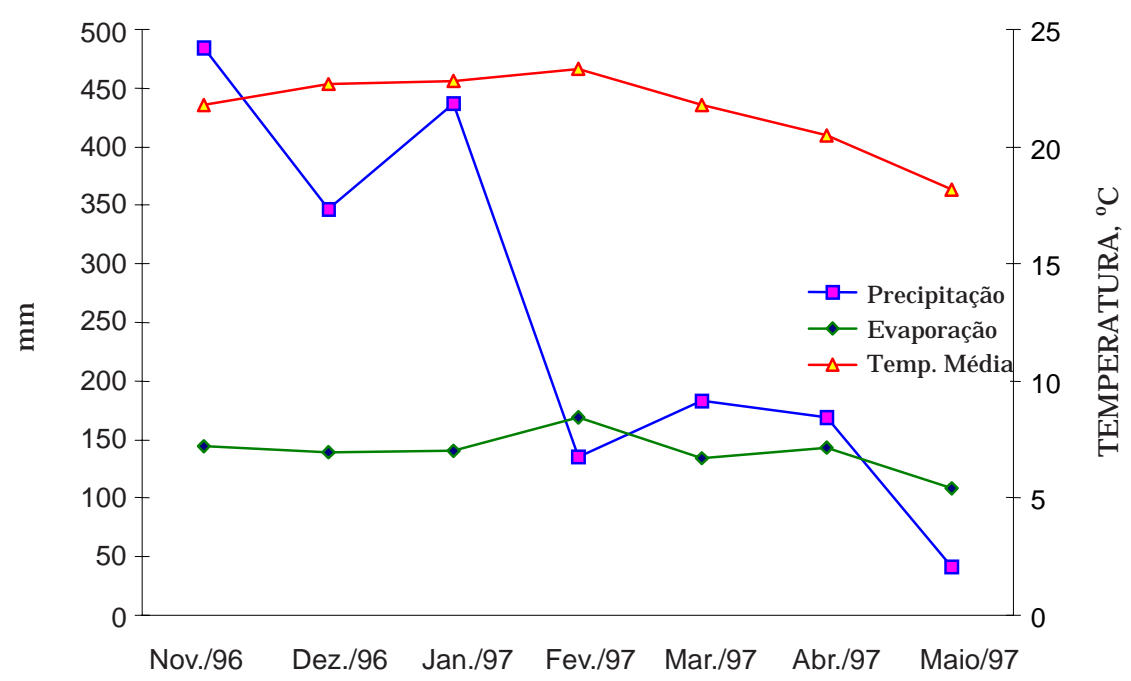

Figura 1. Médias mensais de precipitação, evaporação e temperatura média, observadas no período de novembro de 1996 a maio de 1997, em Sete Lagoas (MG). 
As parcelas com leguminosas, medindo $5 \times 10 \mathrm{~m}$, ficaram divididas em duas de $5 \times 5 \mathrm{~m}$, sendo uma com capina e outra sem capina. Após o preparo do sol o com gradearadora e nivel adora, as leguminosas foram semeadas manualmente em sulcos espaçados de 0,5 m. A quantidade desementes por metrolinear variou de acordo com cada espécie. Após a emergência das plântulas, efetuou-se desbaste, de forma que o estande inicial das espécies fosse: cinco plantas por metrolinear para feijão-de-porco, feijãobravo do Ceará e mucuna-preta, seis plantas por metrolinear para o lab-lab e sete para o guandu.

As leguminosas foram semeadas em novembro de 1996, sem adubação, e ficaram vegetando até completarem o ciclo. As parcelas com leguminosas solteiras receberam uma capina aos $\mathbf{3 0}$ dias da semeadura.

As legumi nosas eas espontâneas foram avaliadas quanto à produtividade de massa de matéria seca e acúmulo de nutrientes pela parte aérea das plantas.

No florescimento das leguminosas, procedeu-se à amostragem, col hendo a parte aérea das plantas em quatro áreas de $0,25 \mathrm{~m}^{2}$ de cada parcela. As leguminosas e as espontâneas foram cortadas à altura do colo, separadas manual mente, identificadas eacondicionadas em sacol as de papel, para posterior determinação da massa da matéria seca e do teor de nutrientes.

A massa da matéria seca foi obtida após a secagem das amostras em estufa de circulação forçada, a $65^{\circ} \mathrm{C}$, por $72 \mathrm{~h}$. Os teores totais decarbono, nitrogênio, cál cio, magnésio, fósforo e potássi o foram determinados a partir de uma amostra composta de cada parcela, do material seco e moído, para cada espécie vegetal. Amostra de 0,2 g de cada material foi mineral izada pela mistura nítrico-perclórica ( $2 \mathrm{ml}$ deácido nítrico: $1 \mathrm{ml}$ deácido perclórico). No extrato, os teores de $\mathrm{Ca}, \mathrm{Mg}, \mathrm{P}$ e $\mathrm{K}$ foram obtidos por espectrometria de emissão plasma; oteor de carbono total, pelo processo de Walkley-Black, descrito por J ackson (1958), com aquecimento, eo de nitrogênio, pel o método da Análise por I njeção em Fluxo - FIA, conforme Zagatto et al. (1981).

Os dados foram submetidos a análises de variância. Para uma mesma leguminosa, as médias de produtividade de massa de matéria seca e de acúmulo de nutrientes, dos diferentes manejos (com e sem capina), foram comparadas pel o teste $\mathrm{F}$ a 5\%. Entre leguminosas, desconsiderando o tipo de manejo, as médias de produtividade de massa de matéria seca e de acúmulo de nutrientes foram comparadas pelo teste de Student-N ewman-Keuls a $5 \%$. As médias de produtividade de massa de matéria seca e de acúmulo de nutrientes pelas espontâneas, dos tratamentos com leguminosas sem capina (consórcios) e da testemunha, foram comparadas pelo teste de Student-N ewman-K euls a $5 \%$. A produtividade total de massa de matéria seca e o acúmulo de nutrientes pela testemunha foram comparados com os das leguminosas, desconsiderando o tipo de manejo, mediante o intervalo de confiança das médias, a 5\%.

\section{RESULTADOS E DISCUSSÃO}

Para uma mesma leguminosa, não foi verificada diferença significativa na produtividade de massa de matéria seca total (MST) entre o plantio consorciado (manejo sem capina) e o sol teiro (manejo com capina) (Quadro 2). A testemunha apresentou MST menor que os tratamentos com feijão-de-porco, feijão-bravo do Ceará e mucuna-preta e não diferenciou significativamente dos tratamentos com guandu e lab-lab (Quadros 2 e 3). Esses dados comprovam o potencial das leguminosas em produzir biomassa, conforme citaram outros autores (Neme, 1949; Schaaffhausen, 1968; Costa, 1993), e demonstram que a presença de espontâneas não reduz a produtividade total de biomassa do sistema consorciado em relação às legumi nosas sol teiras.

Para três das cincol eguminosas estudadas (feijãode-porco, lab-lab e guandu), a produtividade de massa de matéria seca pela leguminosa (MSL) foi maior na ausência de espontâneas que no consórcio (Quadro 2). Por outro lado, a presença de leguminosas reduziu a produção de biomassa pelas espontâneas, uma vez quea produtividade de massa de matéria seca pelas espontâneas (MSE) na testemunha foi maior que nos consórcios com leguminosas. Nos consórcios com mucuna-preta, ela foi menor que nos demais (Quadro 2). As leguminosas exerceram sobreas espontâneas efeitos deabafamentoe repressão. Possivelmente, estiveram presentes também efeitos al el opáticos, como citados por N eme et al. (1954), Neme (1960), Magalhães \& Franco (1960), Magalhães \& Franco (1962), Magalhães (1964), Lorenzi (1984) e Medeiros (1989). A mucuna-preta mostrou-se mais eficiente em produzir esses efeitos.

O feijão-bravo do Ceará apresentou maior produtividade de massa de matéria seca (MSL) e maior acúmul o de todos os nutrientes estudados (CL, $\mathrm{NL}, \mathrm{PL}, \mathrm{KL}, \mathrm{CaL}$ eMgL ), seguido por mucuna-preta e feijão-de-porco (Quadros 2 e 4), destacando-se, dentre as leguminosas estudadas, como a mais promissora em termos de aporte de fitomassa e ciclagem de nutrientes.

Os baixos valores de produção de biomassa obtidos para o guandu, em relação a feijão-bravo do Ceará, feijão-de-porco e mucuna-preta, contrariando os dados obtidos por Alvarenga et al . (1995), devemse ao fato de o guandu não ter atingido seu pleno crescimento por ocasião da amostragem.

O sistema com apenas as espontâneas (testemunha) mostrou-se menos eficiente que os 


\section{Quadro 2. Produtividade de biomassa e carbono e nitrogênio acumulados pelas leguminosas e pelas espontâneas}

\begin{tabular}{|c|c|c|c|c|c|c|c|c|c|c|}
\hline Tratamento & Manejo & MSL & MSE & MST & CL & CE & $\mathbf{C T}$ & NL & NE & NT \\
\hline & & \multicolumn{9}{|c|}{$-\mathrm{kg} \mathrm{ha}^{-1}$} \\
\hline \multirow{3}{*}{ F eijão-de-porco } & c/capina & $7.564 a$ & - & 7.564 & $2.781 \mathrm{a}$ & - & 2.781 & $206 a$ & - & $206 a$ \\
\hline & s/capina & $5.371 \mathrm{~b}$ & - & 6.406 & $2.031 \mathrm{~b}$ & - & 2.405 & $123 \mathrm{~b}$ & - & 143 b \\
\hline & Média & $6.468 \mathrm{~B}$ & $1.035 \mathrm{CD}$ & $6.985 \mathrm{~B}$ & $2.406 \mathrm{~B}$ & $374 \mathrm{CD}$ & $2.593 \mathrm{~B}$ & $165 \mathrm{~A}$ & $19 \mathrm{CD}$ & $174 \mathrm{AB}$ \\
\hline \multirow{3}{*}{$\begin{array}{l}\text { Feijão-bravo } \\
\text { do Ceará }\end{array}$} & c/capina & $\begin{array}{l}8.808 \\
7.252\end{array}$ & - & 8.808 & 3.213 & - & 3.213 & 222 & - & 222 \\
\hline & s/capina & 7.252 & - & 9.586 & 2.721 & - & 3.581 & 191 & - & 228 \\
\hline & Média & $8.030 \mathrm{~A}$ & $2.334 \mathrm{~B}$ & $9.197 \mathrm{~A}$ & $2.967 \mathrm{~A}$ & 860 B & $3.397 \mathrm{~A}$ & $206 \mathrm{~A}$ & 37 BC & $225 \mathrm{~A}$ \\
\hline \multirow[t]{2}{*}{ Lab-lab } & $\begin{array}{l}\text { c/capina } \\
\text { s/capina }\end{array}$ & $\begin{array}{r}3.713 a \\
736 b\end{array}$ & - & $\begin{array}{l}3.713 \\
2.687\end{array}$ & $\begin{array}{r}1.327 \mathrm{a} \\
274 \mathrm{~b}\end{array}$ & - & $\begin{array}{r}1.327 \\
963\end{array}$ & $\begin{array}{r}109 a \\
20 b\end{array}$ & - & $\begin{array}{r}109 \\
59\end{array}$ \\
\hline & Média & $2.225 \mathrm{D}$ & $1.951 \mathrm{BC}$ & $3.200 \mathrm{C}$ & 801 D & 689 BC & $1.145 \mathrm{D}$ & $64 \mathrm{~B}$ & $40 \mathrm{BC}$ & $84 C D$ \\
\hline \multirow[t]{2}{*}{ Mucuna preta } & $\begin{array}{l}\text { c/capina } \\
\text { s/capina }\end{array}$ & $\begin{array}{l}6.615 \\
6.987\end{array}$ & - & $\begin{array}{l}6.615 \\
7.153\end{array}$ & $\begin{array}{l}2.588 \\
2.684\end{array}$ & - & $\begin{array}{l}2.588 \\
2.743\end{array}$ & $\begin{array}{l}196 \\
214\end{array}$ & - & $\begin{array}{l}196 \\
217\end{array}$ \\
\hline & Média & $6.801 \mathrm{~B}$ & $166 \mathrm{D}$ & $6.884 \mathrm{~B}$ & $2.636 \mathrm{AB}$ & $59 \mathrm{D}$ & $2.666 \mathrm{~B}$ & $205 \mathrm{~A}$ & $4 \mathrm{D}$ & $206 \mathrm{~A}$ \\
\hline \multirow[t]{2}{*}{ Guandu } & $\begin{array}{l}\text { c/capina } \\
\text { s/capina }\end{array}$ & $\begin{array}{l}5.118 a \\
2.867 b\end{array}$ & - & $\begin{array}{l}5.118 \\
5.768\end{array}$ & $\begin{array}{l}2.030 \mathrm{a} \\
1.120 \mathrm{~b}\end{array}$ & - & $\begin{array}{l}2.030 \\
2.196\end{array}$ & $\begin{array}{r}137 a \\
67 b\end{array}$ & - & $\begin{array}{l}137 \\
120\end{array}$ \\
\hline & Média & $3.993 \mathrm{C}$ & $2.901 \mathrm{AB}$ & $5.443 \mathrm{BC}$ & $1.575 \mathrm{C}$ & $1.076 \mathrm{AB}$ & $2.113 \mathrm{C}$ & $102 \mathrm{~B}$ & $53 A B$ & $129 \mathrm{BC}$ \\
\hline Testemunha & & & $3.740 \mathrm{~A}$ & 3.740 & - & $1.380 \mathrm{~A}$ & 1.380 & - & $68 \mathrm{~A}$ & 68 \\
\hline
\end{tabular}

MS - massa de matéria seca; L - leguminosa; E - espontâneas; T - total; C - carbono; N - nitrogênio. Médias de leguminosas seguidas pela mesma letra maiúscula, na coluna, não diferem entre si, pel o teste de Student-N ewman-Keuls, a 5\%. Para a mesma leguminosa, médias de manejos, seguidas por letras minúsculas, diferem entre si, pelo teste $\mathrm{F}$, a $5 \%$.

\section{Quadro 3. Comparação entre as leguminosas e a testemunha quanto à produção total de biomassa e acúmulo total de nutrientes}

\begin{tabular}{lccccccc}
\hline & MST & CT & NT & PT & KT & CaT & MgT \\
\hline FdP X Tes & $*$ & $*$ & $*$ & ns & ns & $*$ & ns \\
FbC X Tes & $*$ & $*$ & $*$ & $*$ & $*$ & $*$ & $*$ \\
LabX Tes & ns & ns & ns & ns & ns & ns & ns \\
MucX Tes & $*$ & $*$ & $*$ & $*$ & ns & ns & ns \\
Gua X Tes & ns & ns & $*$ & ns & ns & ns & ns \\
\hline
\end{tabular}

MST - massa de matéria seca total; CT - carbono total; NT nitrogênio total; PT - fósforo total; KT - potássio total; CaT cálcio total; MgT - magnésio total. ns e * =não-significativo e significativo, respectivamente, pelo intervalo de confiança, a $5 \%$.

demais sistemas (leguminosas sol teiras e consórcios de leguminosa e espontânea), quanto ao aporte de fitomassa e a quantidade de nutrientes que possibilita ciclar, visto que produziu menos biomassa e acumulou menor conteúdo de nutrientes, embora a diferença não tenha sido significativa em alguns casos (Quadros 2, 3 e 4).
A contribuição de cada espécie de espontânea na produtividade de biomassa foi pequena em todos os consórcios (Quadro 5).

Em termos de nutrientes, foram poucas as espontâneas que apresentaram teores de cálcio e nitrogênio próximos ou superiores aos das leguminosas. Para potássio, magnésio e fósforo, a tendência se inverteu. A maioria das espontâneas apresentou maiores teores de potássio e magnésio e, várias delas, maiores teores de fósforo (Quadro 5).

Dentre as espontâneas, destacaram-se, pelos teores de fósforo, potássio e magnésio apresentados: Portulaca oleracea, com teor de potássio mais de quatro vezes e de magnésio três vezes o das leguminosas; Euphorbia heterophylla, com teores de fósforo e potássio mais de três vezes o das leguminosas; Bidens pilosa e Commelina benghalensis, com teores de fósforo, potássio e magnésio maiores que o das leguminosas, sendo mais de três vezes o teor de potássio; e Melampodium perfol iatum, com teores de potássio e magnésio mais que duas vezes o das leguminosas. Essas espécies apresentaram-se como promissoras em termos de potencial para a ciclagem de fósforo, potássio e magnésio. 
Quadro 4. Fósforo, potássio, cálcio e magnésio acumulados pelas leguminosas e pelas espontâneas

\begin{tabular}{|c|c|c|c|c|c|c|c|c|c|c|c|c|c|}
\hline Tratamento & Manejo & PL & PE & PT & $\mathbf{K L}$ & KE & KT & CaL & CaE & CaT & MgL & MgE & MgT \\
\hline & & \multicolumn{12}{|c|}{$\mathrm{kg} \mathrm{ha}^{-1}$} \\
\hline \multirow{2}{*}{ Feijão-de-porco } & $\begin{array}{l}\text { c/capina } \\
\text { s/capina }\end{array}$ & $\begin{array}{l}5,6 \mathrm{a} \\
3,0 \mathrm{~b}\end{array}$ & - & $\begin{array}{l}5,6 \\
3,9\end{array}$ & $\begin{array}{l}62 \mathrm{a} \\
25 \mathrm{~b}\end{array}$ & - & $\begin{array}{l}62 \mathrm{a} \\
41 \mathrm{~b}\end{array}$ & $\begin{array}{l}76 \mathrm{a} \\
51 \mathrm{~b}\end{array}$ & - & $\begin{array}{l}76 \\
56\end{array}$ & $\begin{array}{l}7,2 \mathrm{a} \\
4,9 \mathrm{~b}\end{array}$ & - & $\begin{array}{l}7,2 \\
6,3\end{array}$ \\
\hline & Média & $4,3 \mathrm{~B}$ & $0,9 \mathrm{~B}$ & $4,8 \mathrm{~B}$ & $44 \mathrm{~B}$ & $16 \mathrm{C}$ & $52 \mathrm{BC}$ & $64 \mathrm{~B}$ & $5 \mathrm{~B}$ & $66 \mathrm{~B}$ & $6,1 \mathrm{~A}$ & $1,4 \mathrm{C}$ & $6,8 \mathrm{~B}$ \\
\hline \multirow[t]{2}{*}{$\begin{array}{l}\text { Feijão-bravo } \\
\text { do Ceará }\end{array}$} & $\begin{array}{l}\text { c/capina } \\
\text { s/capina }\end{array}$ & $\begin{array}{l}6,8 \\
6,0\end{array}$ & $\begin{array}{l}- \\
-\end{array}$ & $\begin{array}{l}6,8 \mathrm{a} \\
8,7 \mathrm{~b}\end{array}$ & $\begin{array}{l}74 \mathrm{a} \\
56 \mathrm{~b}\end{array}$ & - & $\begin{array}{l}74 \mathrm{a} \\
91 \mathrm{~b}\end{array}$ & $\begin{array}{r}113 a \\
81 b\end{array}$ & - & $\begin{array}{r}113 \\
96\end{array}$ & $\begin{array}{l}8,5 \\
6,6\end{array}$ & $\begin{array}{l}- \\
-\end{array}$ & $\begin{array}{l}8,5 \\
9,8\end{array}$ \\
\hline & Média & $6,4 \mathrm{~A}$ & $2,7 \mathrm{~A}$ & $7,8 \mathrm{~A}$ & $65 \mathrm{~A}$ & $35 \mathrm{~B}$ & $83 \mathrm{~A}$ & $97 \mathrm{~A}$ & $15 \mathrm{~A}$ & $105 \mathrm{~A}$ & $7,6 \mathrm{~A}$ & $3,2 \mathrm{~B}$ & $9,2 \mathrm{~A}$ \\
\hline \multirow[t]{2}{*}{ Lab-lab } & $\begin{array}{l}\text { c/capina } \\
\text { s/capina }\end{array}$ & $\begin{array}{l}4,1 \mathrm{a} \\
0,7 \mathrm{~b}\end{array}$ & - & $\begin{array}{l}4,1 \\
2,8\end{array}$ & $\begin{array}{r}35 \mathrm{a} \\
4 \mathrm{~b}\end{array}$ & - & $\begin{array}{l}35 \\
34\end{array}$ & $\begin{array}{r}41 \mathrm{a} \\
8 \mathrm{~b}\end{array}$ & - & $\begin{array}{l}41 \\
19\end{array}$ & $\begin{array}{l}4,5 \mathrm{a} \\
0,7 \mathrm{~b}\end{array}$ & - & $\begin{array}{l}4,5 \\
3,3\end{array}$ \\
\hline & Média & $2,4 \mathrm{~B}$ & $2,1 \mathrm{~B}$ & $3,5 \mathrm{~B}$ & $20 \mathrm{C}$ & $29 \mathrm{~B}$ & $34 \mathrm{C}$ & $24 \mathrm{C}$ & $12 \mathrm{~A}$ & $30 \mathrm{C}$ & $2,6 \mathrm{~B}$ & $2,6 \mathrm{~B}$ & $3,9 \mathrm{C}$ \\
\hline \multirow[t]{2}{*}{ Mucuna preta } & $\begin{array}{l}\text { c/capina } \\
\text { s/capina }\end{array}$ & $\begin{array}{l}6,7 \\
6,8\end{array}$ & - & $\begin{array}{l}6,7 \\
7,0\end{array}$ & $\begin{array}{l}53 \\
58\end{array}$ & - & $\begin{array}{l}53 \\
61\end{array}$ & $\begin{array}{l}34 \\
35\end{array}$ & - & $\begin{array}{l}34 \\
36\end{array}$ & $\begin{array}{l}5,8 \\
5,8\end{array}$ & - & $\begin{array}{l}5,8 \\
6,1\end{array}$ \\
\hline & Média & $6,8 \mathrm{~A}$ & $0,2 \mathrm{C}$ & $6,9 \mathrm{~A}$ & $55 \mathrm{~B}$ & $3 \mathrm{C}$ & $57 \mathrm{~B}$ & $35 \mathrm{C}$ & $1 \mathrm{~B}$ & $35 \mathrm{C}$ & $5,8 \mathrm{~A}$ & $0,3 \mathrm{C}$ & $6,0 \mathrm{~B}$ \\
\hline \multirow[t]{2}{*}{ Guandu } & $\begin{array}{l}\text { c/capina } \\
\text { s/capina }\end{array}$ & $\begin{array}{l}4,7 \mathrm{a} \\
2,2 \mathrm{~b}\end{array}$ & - & $\begin{array}{l}4,7 \\
4,3\end{array}$ & $\begin{array}{l}38 \mathrm{a} \\
15 \mathrm{~b}\end{array}$ & - & $\begin{array}{l}38 \\
51\end{array}$ & $\begin{array}{l}22 \\
10\end{array}$ & - & $\begin{array}{l}22 \\
23\end{array}$ & $\begin{array}{l}3,6 \\
1,7\end{array}$ & - & $\begin{array}{l}3,6 \\
4,8\end{array}$ \\
\hline & Média & $3,5 \mathrm{~B}$ & $2,1 \mathrm{~B}$ & $4,5 \mathrm{~B}$ & $26 \mathrm{C}$ & 36 B & $44 \mathrm{BC}$ & $=16 \mathrm{C}$ & $13 \mathrm{~A}$ & $22 \mathrm{C}$ & $2,7 \mathrm{~B}$ & $3,1 \mathrm{~B}$ & $4,2 \mathrm{C}$ \\
\hline Testemunha & & - & $3,0 \mathrm{~A}$ & 3,0 & - & $52 \mathrm{~A}$ & 52 & - & $17 \mathrm{~A}$ & 17 & - & $4,5 \mathrm{~A}$ & 4,5 \\
\hline
\end{tabular}

P - fósforo; L - leguminosa; E - espontâneas; T - total; K - potássio; Ca - cálcio; Mg - magnésio. Médias de leguminosas seguidas pela mesma letra maiúscula, na coluna, não diferem entre si, pelo teste de Student-Newman-Keuls, a 5\%. Para a mesma leguminosa, médias de manejos, seguidas por letras minúsculas, diferem entre si, pelo teste $\mathrm{F}$, a $5 \%$.

Quadro 5. Produtividade de massa de matéria seca e teor de nutrientes das leguminosas e das espontâneas

\begin{tabular}{|c|c|c|c|c|c|c|c|c|c|c|c|c|}
\hline \multirow{2}{*}{ Espécie } & \multicolumn{6}{|c|}{ Massa de matéria seca (Tratamento) } & \multicolumn{6}{|c|}{ Nutriente (M édia do tratamento) } \\
\hline & $F p+E$ & $\mathbf{F b}+\mathbf{E}$ & $\mathbf{L b}+\mathbf{E}$ & $M c+E$ & $\mathbf{G d}+\mathbf{E}$ & Tes & $\mathbf{P}$ & $\mathbf{K}$ & $\mathrm{Ca}$ & Mg & C & $\mathbf{N}$ \\
\hline & \multicolumn{6}{|c|}{$-\mathrm{kg} \mathrm{ha}^{-1}$} & \multicolumn{6}{|c|}{ - dag kg-1 } \\
\hline Leguminosa & 5.371 & 7.252 & 736 & 6.987 & 2.867 & - & 0,08 & 0,63 & 0,81 & 0,09 & 38,0 & 2,61 \\
\hline Bidens pilosa & 105 & 625 & 228 & 25 & 384 & 247 & 0,15 & 1,97 & 0,68 & 0,13 & 36,0 & 1,95 \\
\hline Blainvillea Iatifolia & - & 144 & - & & 12 & 78 & 0,10 & 1,74 & 0,88 & 0,14 & 33,3 & 2,26 \\
\hline Brachiaria plantaginea & 12 & 59 & 29 & - & 40 & - & 0,05 & 1,13 & 0,40 & 0,16 & 37,6 & 1,70 \\
\hline Cenchrus echinatus & 79 & 195 & 265 & 11 & 942 & 1297 & 0,06 & 1,20 & 0,21 & 0,08 & 38,8 & 1,69 \\
\hline Cynodon dactylon & 182 & 251 & 106 & 4 & 320 & 76 & 0,06 & 0,83 & 0,25 & 0,06 & 38,2 & 1,35 \\
\hline Cyperus rotundus & 22 & - & 46 & - & 21 & 20 & 0,05 & 1,46 & 0,29 & 0,08 & 37,3 & 1,50 \\
\hline Chenopodium album & - & - & 20 & - & - & - & 0,12 & 1,08 & 1,48 & 0,10 & 35,3 & 2,10 \\
\hline Commelina benghalensis & 93 & 52 & 192 & 80 & 144 & 263 & 0,10 & 2,30 & 0,52 & 0,16 & 33,0 & 1,69 \\
\hline Croton glandulosus & - & 9 & - & - & 31 & - & 0,08 & 0,76 & 0,67 & 0,19 & 36,4 & 2,48 \\
\hline Digitaria horizontal is & 87 & 72 & 147 & - & 172 & 206 & 0,08 & 1,52 & 0,26 & 0,15 & 37,1 & 1,53 \\
\hline Eleusine indica & - & - & 40 & - & 76 & 15 & 0,08 & 1,04 & 0,39 & 0,13 & 38,2 & 1,69 \\
\hline Emilia sanchifolia & - & - & 9 & - & 20 & - & 0,08 & 1,65 & 0,74 & 0,14 & 36,4 & 2,15 \\
\hline Euphorbia heterophylla & - & - & - & - & - & 10 & 0,28 & 1,98 & 0,54 & 0,09 & 35,9 & 1,44 \\
\hline Mel ampodium perfoliatum & 45 & 701 & 401 & 22 & 113 & 437 & 0,13 & 1,65 & 0,94 & 0,20 & 36,1 & 1,75 \\
\hline Nicandra physaloides & 18 & - & - & - & - & 25 & 0,11 & 1,22 & 0,48 & 0,14 & 38,3 & 1,55 \\
\hline Panicum maximum & 308 & 223 & 276 & - & 429 & 889 & 0,07 & 1,43 & 0,34 & 0,13 & 36,9 & 2,43 \\
\hline Portulaca ol eracea & - & - & - & - & - & 16 & 0,08 & 3,03 & 0,40 & 0,27 & 33,3 & 1,91 \\
\hline Raphanus raphanistrum & 33 & - & - & - & - & - & 0,05 & 1,07 & 0,73 & 0,07 & 36,7 & 1,67 \\
\hline Richardia brasiliensis & 41 & - & 95 & 1 & 139 & 120 & 0,08 & 1,23 & 1,72 & 0,13 & 27,8 & 1,91 \\
\hline Sida glaziovii & - & - & 22 & - & - & - & 0,11 & 0,60 & 0,65 & 0,16 & 36,8 & 2,81 \\
\hline Spermacoce latifol a & 10 & 3 & 75 & - & 58 & 41 & 0,10 & 1,39 & 1,04 & 0,13 & 32,0 & 2,51 \\
\hline Outras & - & - & - & 23 & - & - & 0,09 & 1,34 & 0,23 & 0,11 & 37,2 & 1,97 \\
\hline
\end{tabular}

$\mathrm{Fp}+\mathrm{E}=$ feijão-de-porco mais espontâneas; $\mathrm{Fb}+\mathrm{E}$ = feijão-bravo do Ceará mais espontâneas; $\mathrm{Lb}+\mathrm{E}=$ lab-lab mais espontâneas; $\mathrm{Mc}+\mathrm{E}=$ mucuna-preta mais espontâneas; $\mathrm{Gd}+\mathrm{E}=$ guandu mais espontâneas e Tes =Testemunha. 


\section{CONCLUSÕES}

1. A produtividade de biomassa e o acúmulo de nutrientes nos sistemas de leguminosas cultivadas com capina não foram significativamente diferentes dos sem capina. Esses foram maiores nos sistemas com leguminosas que no sistema com apenas as espontâneas.

2. Os sistemas em que a leguminosa introduzida foi o feijão-bravo do Ceará apresentaram maiores val ores de produtividade de biomassa e acúmulo de nutrientes que os demais.

3. As espontâneas apresentaram menores teores de nitrogênio e cálcio que as leguminosas. No entanto, a maioria apresentou maiores teores de potássio e magnésio e, várias delas, maiores teores de fósforo.

4. Dentreas espontâneas, destacaram-se, quanto aos teores de fósforo, potássio e magnésio apresentados: Portulaca ol eracea, Euphorbia heterophylla, Bidens pilosa, Commelina benghalensis e Melanpodium perfol iatum.

\section{LITERATURA CITADA}

ALVARENGA, R.C.; COSTA, L.M.; MOURA FILHO, W. \& REGAZZI, A.J . Características de al guns adubos verdes de interesse para a conservação e recuperação de solos. Pesq. Agropec. Bras., 30:175-185, 1995.

COSTA, M.B.B. Adubação verde no sul do Brasil. Rio deJ aneiro, AS-PTA, 1993. 346p.

DE-POLLI, H. \& CHADA, S.S. Adubação verde incorporada ou em cobertura na produção de milho em solo de baixo potencial de produtividade. R. Bras. Ci. Solo, 13:287-293, 1989.

J ACKSON, M.L. Soil chemical analysis. New J ersey, PrenticeHall, 1958. 498p.

KIEHL, E.J. Contribuição para o estudo da poda e da decomposição de adubos verdes. Piracicaba, Escola Superior de Agricultura Luiz de Queiroz, 1960. 113p. (Tese de Livre Docência)

LATHWELL, D.J. Legume green manure. Principles for management based on recent research. Soil Management Collaborative Research Support Program, 1990. 30p. (Trop Soils Bulletim, 90-01)
LORENZI, H. Inibição alelopática de plantas daninhas. In: FUNDAÇÃO CARGIL. Adubação verde no Brasil. Campinas, 1984. p.183-198.

MAGALHÃES, A.C. Efeito inibidor de extratos de plantas de feijão-de-porco sobre o desenvolvimento da tiririca. Bragantia, 23:29-34, 1964.

MAGALHÃES, A.C. \& FRANCO, C.M. Efeito do extrato de nódulos de raízes de feijão-de-porco sobre o desenvolvimento de tubérculos de tiririca. In: SEMINÁRIO BRASILEIRO DE HERBICIDAS E ERVAS DANINHAS, 4., Rio deJ aneiro, 1960. Anais. Rio deJ aneiro, SociedadeBrasileira de Plantas Daninhas, 1960. p.59-63.

MAGALHÃES, A.C. \& FRANCO, C.M. Toxicidade do feijão-deporco sobre a tiririca. Bragantia, 21:53-58, 1962.

MANHÃES, M.S. \& CRUZ FILHO, D.J. Avaliação dos rendimentos de leguminosas para adubação verde na zona canavieira do estado de São Paulo. Saccharum, 6:40-44, 1983.

MEDEIROS, A.R.M. Determinação de potencialidades alelopáticas em agroecossistemas. Piracicaba, Escola Superior de Agricultura Luiz de Queiroz, 1989. 92p. (Tese de Doutorado)

NEME, N.A. Leguminosas para adubos verdes e forragens. Campinas: Instituto Agronômico, 1949. 28p. (Boletim 109)

NEME, N.A. Combate a tiririca. Agron., 12:5-6, 1960.

NEME, N.A.; MIRANDA, H.S. \& FORSTER, R. A ação da cultura do feijão-de-porco no combate a tiririca. In: CONGRESSO PAN-AMERICANO DE AGRON OMIA, 2., Piracicaba, 1954. Anais. Piracicaba, Escola Superior de Agricultura Luiz de Queiroz, 1954. p.261-262.

PARYLAK, D. Uptake of nutrients by weeds and winter triticale at different development stages. Zeszyty Naukowe Akademii. Rolniczej W Szczecinie Rolnictwo, 58:185-188, 1994.

QASEM, J.R. Nutrient accumulation by weeds and their associated vegetable crops. J . Hortic. Sci., 67:189-195, 1992.

SCHAAFFHAUSEN, R.V. Recuperação econômica de solos em regiões tropicais através de leguminosas e mi croelementos. In: CONGRESO LATINO-AMERICANO DE BIOLOGIA DO SOLO, 2., Santa Maria, 1968. Anais. Santa Maria, Universidade Federal de Santa Maria, 1968. p 1-12.

ZAGATTO, E.A.G.; J ACINTHO, A.O.; REIS, B.F.; KRUG, F.J .; BERGAMIN FILHO, H.; PESSENDA, L.C.R.; MORTATTI, J . \& GINÉ, M.F. Manual de análises de plantas e águas empregando sistemas de injeção em fluxo. São Paulo, Universidade de São Paulo, Centro de Energia Nuclear na Agricultura, 1981. 96p. 